Barry Leventhal

is statistics director of Berry

Consulting, a leading

provider of consultancy

services in customer

relationship management and database analysis. His

previous career experience

includes market research

and geodemographics.
Keywords: Market research, customer research, database marketing, data fusion, customer relationship management, customer knowledge
The CRM approach requires customer knowledge to support management decisions

\section{Are market research and customer research the same thing? The implications for linking to external data}

\author{
Barry Leventhal \\ Received (in revised form): 16 November 1999
}

\begin{abstract}
Market research and customer research are two forms of individuallevel surveys that may be modelled on to external databases. This paper examines their differences and how these affect their linkage to other information sources.
\end{abstract}

\section{Introduction}

In the launch issue of Interactive Marketing, Webber and Sleight discussed the fusion of market research and database marketing ${ }^{1}$ and whether the early initiatives by suppliers herald the birth of a new discipline. They used the results of interviews with a number of practitioners in the field, including this author.

The aims of this paper are to outline how the 'fusion' process operates, consider the implications of using either market research or customer research surveys as an input, and discuss the differences between these two sources of research.

\section{Why link databases with research?}

During the 1990s, the term 'database marketing' has given way to the phrase 'customer relationship management' (CRM) for many who operate in the direct marketing industry. It is an approach that aims to be customer-focused, delivering the right products and services to the right customers via the most appropriate channels. However, CRM is not just about direct marketing - it spans all stages in managing customers, from acquisition through to retention and, possibly, win-back.

This approach implies a need to know more about each customer in order to support management decisions. For example, knowledge of a customer's future potential, in terms of purchasing further products, would inform the allocation of sales and servicing channels.

Such knowledge cannot be derived solely from records on the company's customer database. The database can provide details of all dealings with the company, and the channels through which these were conducted, but cannot identify products acquired with competitors or future purchase intentions. The ideal method of obtaining such knowledge is to ask the customer, via a survey or data collection exercise. However, surveys can be resource intensive to undertake, the data collected will age over time unless they are updated, and only a proportion of customers may be prepared to supply this information. 


\author{
In-depth survey data \\ can usually only be \\ captured for a small \\ proportion of \\ customers
}

\author{
The depth of \\ customer knowledge \\ obtained from \\ research may be \\ combined with the \\ breadth of database \\ information
}

In practice, therefore, in-depth survey data can usually only be captured for a small proportion of the customer base. It is therefore desirable to have a procedure that will extrapolate the sample survey results across the entire customer database, at individual level. This process has been called 'survey projection', 'fusion', 'linking' or 'attribution' by different practitioners, but the underlying aim is the same in all cases. The choice of statistical procedure or modelling method can, however, vary according to the nature of the data.

The term 'fusion' is greatly abused, as its true meaning is statistical matching of two datasets collected from different samples of individuals, by comparing their characteristics on a group of common variables. However, it is often used to describe one-to-one matching of the same individuals and is sometimes even confused with model building!

True data fusion has mainly been deployed in the market research world, in order to link surveys together and create single-source data. ${ }^{2}$ Although the technique could potentially enhance customer databases, this application has not been well researched and so will not be considered in this paper.

Therefore, to avoid confusion, we will employ the term 'linking' to mean the merging of research information on to customer databases.

The linking process may be conducted with survey data from either market research or customer research - it is crucial for a potential user to understand the differences between the two and their implications, which are discussed more fully in this paper.

Either source will allow the depth of customer knowledge obtained from research to be combined with the breadth of database information, to gain a better understanding of customers and their needs. This can then be applied for improved management and communications at an individual level, or for planning marketing strategy at a group level.

\section{What do research and database techniques provide?}

\section{The role of research}

Research information is often perceived to be of strategic value rather than for tactical use. However, linkage with customer databases extends the research role into operational and tactical areas.

Research techniques tend to collect information about all products acquired in a market - for example, all savings accounts rather than solely savings held with Company X. Therefore, research can deliver marketwide data, can identify use of competitors, and can help to measure Company X's 'share of wallet' among its customers.

Attitudinal questions can also be asked, for example on lifestyle, reasons for saving, product preferences and satisfaction. Future intentions to move house or retire can similarly be gathered. Demographic attributes are invariably captured, typically including life stage, social class and income. Newspaper readership and weight of TV viewing are sometimes included to help in selecting advertising media. 
Leventhal

\author{
Database stores \\ a record of product \\ holdings, \\ transactional \\ behaviour, \\ communications \\ history and contact \\ preferences
}

Research may be designed to represent the entire population or may be focused on specific sub-populations, such as lapsed, current and prospective customers.

\section{The role of database information}

Databases identify customers and prospects, and so may be employed for direct communications and other management purposes. However, beyond the basic name and address, demographic attributes are likely to be very limited.

The main strength of the database lies in recording past and present products held with the company, together with associated transactional data if appropriate. For example, in a bank database, amounts deposited and withdrawn from each of the customer's accounts would be stored as a time series and regularly updated.

The database should also hold a contact history of past communications, responses to campaigns and channel preferences for each customer.

Key propensities and scores may be modelled and predicted for each customer on the database, including cross-sell and up-sell propensities, risk of attrition and long-term profitability values.

\section{An approach to linking databases with research}

In order to link these disparate sources, a 'bridge' is required containing common information present in both datasets. However, as implied by their different roles, it is frequently the case that they will have very few attributes in common.

One option is to use geodemographic data as the bridge. Classifications such as ACORN and MOSAIC can be appended to any postcode, thus research data can be profiled without requiring any further details about the respondent. This has formed the basis for the use of geodemographics in direct marketing; the target group is determined from a research profile and the corresponding neighbourhood types can be selected from a suitable mailing list. The link is made without ever bringing together the research source and database, so the approach is extremely straightforward to apply.

The main disadvantage of this approach is that postcode information tends to be a fairly weak predictor of individual behaviour, thus an individual-level 'bridge' is really required. The conceptual stages in building and utilising this bridge are shown in Figure 1, although the actual process will depend on whether the research data are captured as either a market research or customer research survey.

In concept, the approach entails matching an individual's research responses with the information held in an external database to form a more complete picture of that person. The sample that can be matched in this way is sometimes known as a 'workbench', and forms the testbed for analysis of key criteria derived from the research. Examples would be survey-based segmentations or marketwide measures such as total financial assets. The goal of such analysis would often be to develop models that can be applied to predict the key criteria for all individuals on the external database.

\author{
The workbench \\ sample contains \\ both research \\ responses and \\ database \\ information
}

\section{information tends to be a fairly weak predictor of individual behaviour \\ Postcode}




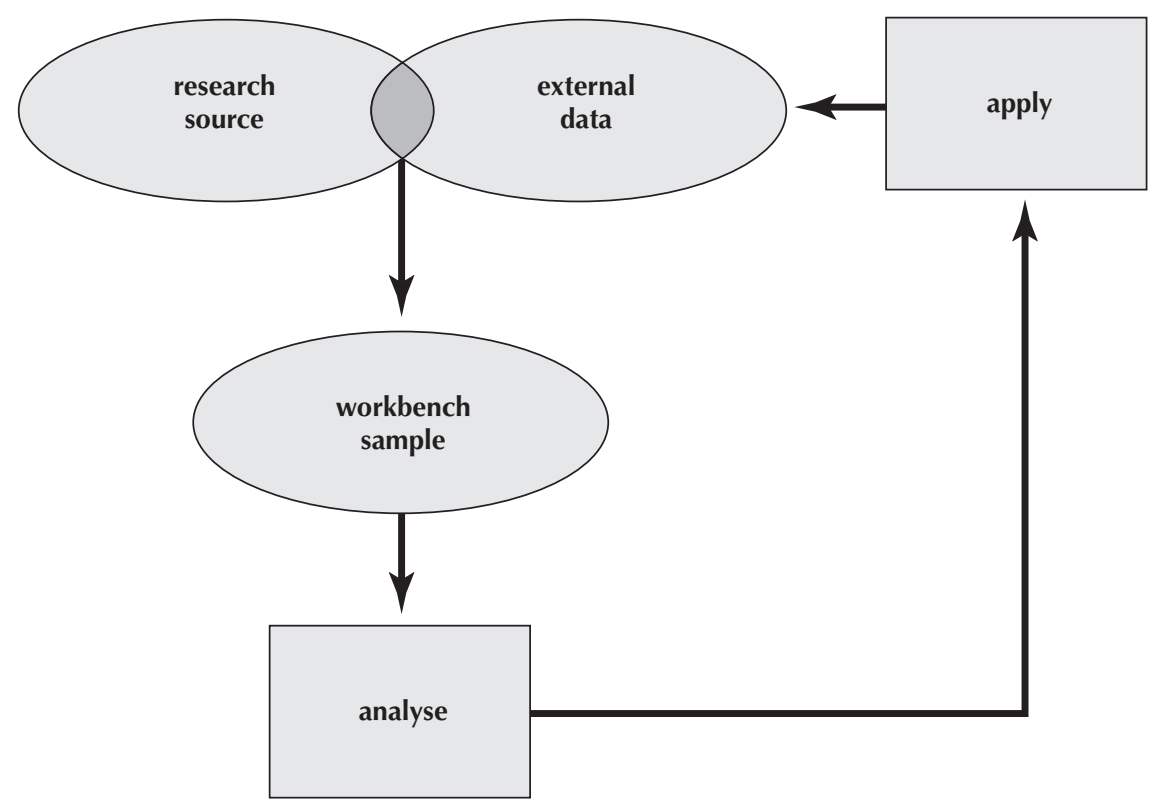

Figure 1: Bridging research and external data Source: Berry Consulting

Although this process can be driven by either market research or customer research surveys, these sources are not the same thing, so it is important that the potential client understands the differences between them and the criteria for deciding which to select.

\section{Main features of market research and customer research surveys}

\section{Market research}

Market research covers a wide range of survey collection and analysis techniques designed to support marketing decisions. These include qualitative and quantitative research — although quantitative surveys are of primary relevance here - on all aspects of consumers in a market, including product purchasing, usage and attitudes. The main forms and attributes of market research are summarised in Table 1.

All market research in the UK must be conducted in accordance with the MRS Code of Conduct, ${ }^{3}$ agreed by the Market Research Society, and must also follow the Data Protection Act. One of the key principles of the MRS Code is that an informant's identity cannot be revealed without their consent to anyone not directly involved in the research, nor used for anything other than research purposes.

One of the key principles of the MRS Code is that the informant's identity cannot be revealed
This principle would appear to prevent the use of market research for linking to external data; however, in 1995 the MRS Professional Standards Committee published a set of guidelines for handling databases, ${ }^{4}$ designed for those working with databases containing personal details of respondents, potential respondents or respondentidentified survey data. These guidelines provided a framework for 
Leventhal

Table 1: Main forms and attributes of market research

\begin{tabular}{|c|c|}
\hline \multicolumn{2}{|l|}{ Research types } \\
\hline Term & Description \\
\hline Quantitative & Any research that provides numerical results \\
\hline - ad hoc & One-off study \\
\hline - continuous & Repeated study \\
\hline — omnibus & Survey for client-sponsored questions \\
\hline - panel & Repeated survey monitoring same respondents \\
\hline — opinion poll & Ad hoc survey of voting intentions \\
\hline Qualitative & Research that explores an issue without quantified results \\
\hline — depth interviews & Unstructured interviews with a single informant \\
\hline — focus groups & Group discussions with around eight informants \\
\hline \multicolumn{2}{|l|}{ Attributes } \\
\hline \multicolumn{2}{|c|}{ Conforms with MRS Code of Conduct (in UK) } \\
\hline \multicolumn{2}{|c|}{ Respondents must be kept anonymous } \\
\hline \multicolumn{2}{|c|}{ Often conducted on sample drawn from the relevant population } \\
\hline \multicolumn{2}{|c|}{ Designed to provide unbiased findings for the total population } \\
\hline
\end{tabular}

The MRS database guidelines provide a framework for researchers to work with database marketers researchers to work with database marketers, and so led to the workbench development described in this paper, and to the 'new discipline' reviewed by Webber and Sleight. ${ }^{5}$

One of the principles of the Data Protection Act is that personal data must be processed fairly. This implies that respondents should be informed that their data may be used for confidential statistical analysis, along with other information about them.

Market researchers employ in-depth techniques such as personal interviews and electronic data capture to collect information that is as accurate and detailed as possible. Surveys are designed and structured to provide unbiased results that can be extrapolated from the sample to the population.

Dependent on the data collection technique selected, it may be expensive to conduct market research on large samples, therefore many of the large-scale industry surveys are syndicated, in order to share the costs among a number of subscribers. These surveys can provide readymade data sources for linking to external data, the main disadvantage being that the questions included are not normally specific to the client. (The exception is the omnibus survey, in which each client pays for the inclusion of certain questions relevant to themselves.)

However, market research can also be undertaken on a bespoke base for one client. Even in this instance, the client is not normally identified to the respondent, in order to avoid the possibility of introducing bias into their responses.

\section{Customer research surveys}

The main attributes of customer research surveys are summarised in Table 2 and discussed more fully below. 


\section{Customer surveys for research purposes may only be used in an aggregated form; this includes statistical analysis and modelling}

\section{Customer research surveys are often considered when the objectives are highly specific to the company}

The UK Data Protection Act and MRS database guidelines apply to customer surveys conducted strictly for research purposes. One of the key guidelines is that, apart from drawing samples for market research surveys, the data collected in customer research are used only in aggregated form for research, modelling or statistical purposes. Also, the data must not be released to a new owner in a form that enables them to be linked to individuals in the database, and any new data owner must agree that they will only use the data for the same purposes.

These conditions do not apply to customer surveys conducted for nonresearch purposes, such as collection of customer details and preferences for future marketing approaches. However, the purpose of the survey must be clearly stated to the respondent, who must be given the opportunity to decline permission for their data to be used in this way.

Customer research surveys are often considered when the research objectives are highly specific, for example:

- to follow up enquirers and identify their reasons for purchase or non-purchase

- to find out how customers view the company's image, literature and so on

- to determine the reasons why customers discontinued with a product or service.

However, the question topics must be chosen with care, as respondents can sometimes be tempted to give answers they believe the company wishes to receive. (This may be a reason to conduct a bespoke piece of market research, rather than a customer survey, in some circumstances.)

The most frequently applied technique is the self-completion postal survey, although telephone surveys are also conducted. With the rapid growth of home computing and e-mail, this may become a further useful channel for customer research.

Cooperation rates tend to be lower in customer research than in market research. For example, in a postal survey of customers, a response rate of 20 per cent or more would be considered to be good, and response rates among inactive customers can be much lower.

\section{The use of each research type for data linking}

The differences between market research and customer research have implications for the way in which the data-linking process can be applied. These are discussed below, together with a case study example for each research type. 
Leventhal

\section{The logistics of workbench creation are designed to maintain respondent confidentiality}

\section{Market research}

The research database matching and workbench creation require a set of logistics that are designed to maintain respondent confidentiality and process large volumes of data as efficiently as possible. The processing is undertaken in several steps, as shown in Figure 2. It is illustrated in the context of matching a survey to a customer database, but the same principles would apply if matching to an external population file, such as the electoral roll.

The first step is to extract the locations of survey respondents - in the UK, these are defined by postcodes - and screen the customer database using the postcode list. This will significantly reduce the size of the file that has to be individually accessed.

For confidentiality reasons, names and addresses are extracted separately from data, each tagged by a unique reference number (URN).

The survey respondents and customers in those postcodes are then matched on name and address, possibly after standardising each address to Post Office format. The name and address match is an inexact process, due to the format variations and errors that can occur. A 'fuzzy' matching procedure is desirable which will accept imperfect matches that have a high likelihood of being the same individual.

The research and customer data items are attached to the matched URNs in a separate location, where the names and addresses are not known. Finally the original URNs are removed, in order to obtain a completely anonymised workbench dataset.

\section{Case study example}

The procedure described here has been applied to match NOP's Financial Research Survey (FRS) to customer databases held by various large

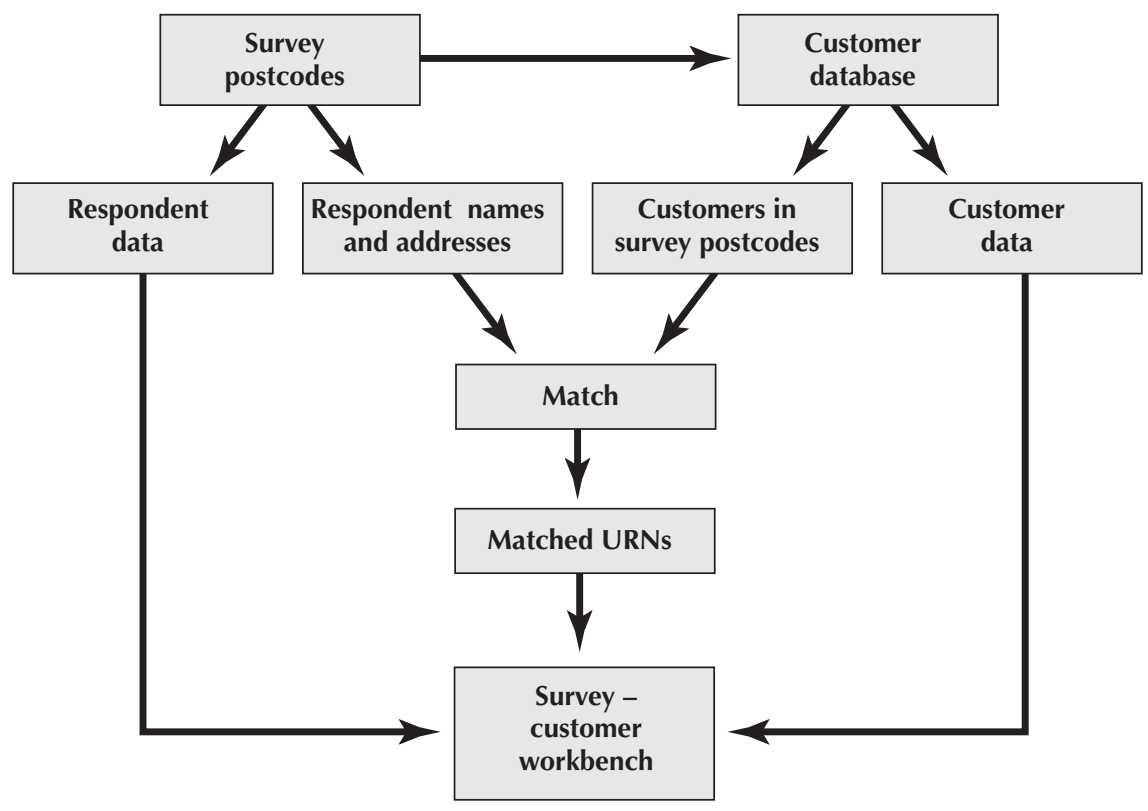

Figure 2: Workbench creation Source: Leventhal ${ }^{6}$ 


\section{The company database should be the sampling frame for a customer research survey}

financial institutions. The main purpose of this match has been to model the NOP/Berry Consulting FRuitS segmentation on to each customer base.

For example, the first subscriber to FRuitS was Prudential, in autumn 1996. Their customer base was matched to the FRS by following the process described above. Attribution models for FRuitS were developed and applied back on to the database. Prudential tested FRuitS as part of a major PEP campaign in spring 1997, with considerable success.

Further details of the workbench creation, and outcomes for different clients, may be found in Leventhal. ${ }^{6}$

\section{Customer research}

The company's database should provide the sampling frame for carrying out a customer research survey and, as the questionnaires can be pre-printed with customer numbers, the logistics of matching the response file and customer data are greatly simplified.

\section{Case study example}

A customer research survey was conducted by an investment house that wanted to gain a better understanding of the attitudes and marketwide behaviour of its investors.

The sample was drawn from the customer database, together with an extract of available transaction data for those investors. The survey responses were matched back to this file on customer number, forming a 'customer lab' database used for research purposes.

A customer segmentation was built using the same sample, and thoroughly profiled by the survey variables. Models were finally developed to assign every customer to a segment, and were applied across the entire customer base (see Figure 3).

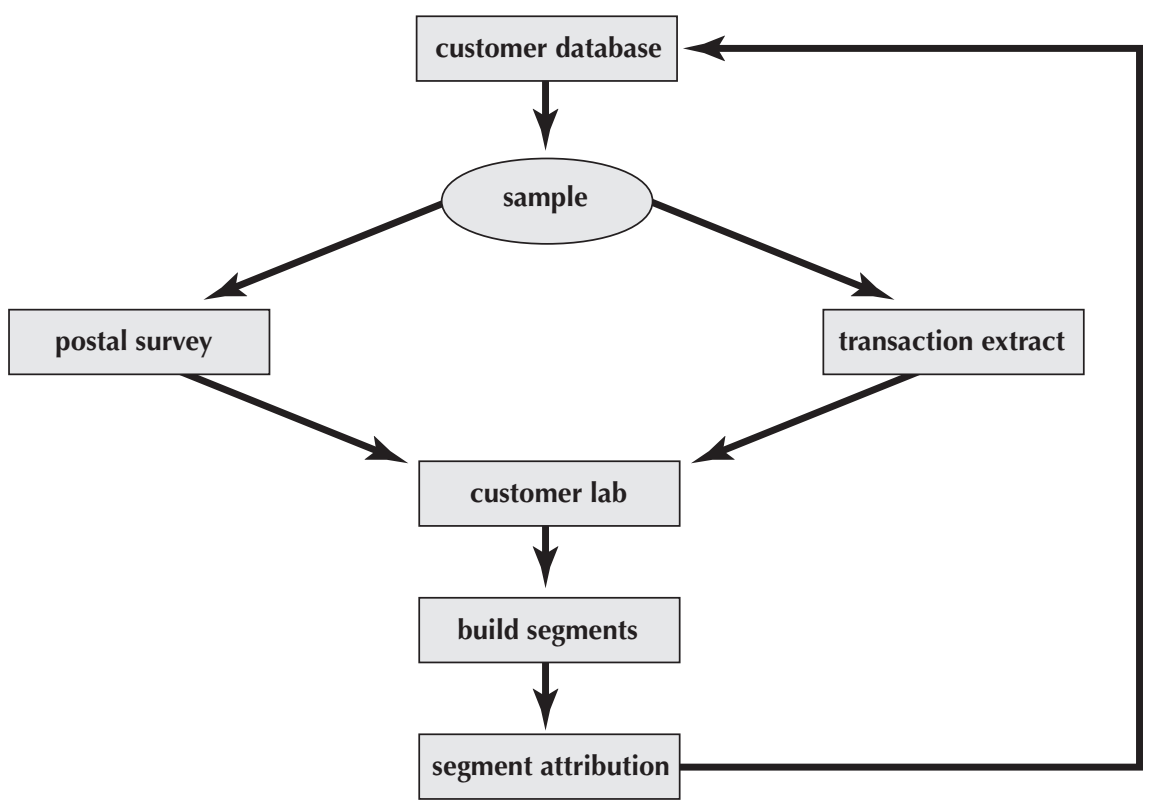

Figure 3: Case study example - investment house Source: Berry Consulting 


\section{Application of these techniques implies a wider range of skills than purley database analysis and IT}

It is unwise to start
the process without
a detailed
development plan
and risk assessment

\section{Issues in applying these techniques}

To apply the techniques described in this paper a company will need to bring together internal and external information in a meaningful way and have the tools to implement resultant models on its customer base. This implies a wider range of skills and expertise than purely database analysis and IT - primarily it requires an in-depth understanding of research sources, data collection techniques and the linkage process.

Some companies may possess all of these skills in-house, usually within their market research, database analysis and IT departments. Nevertheless, if linking to market research data, they will need to work with their research agency and/or one of the specialist providers of 'linkage services'. For the process to work well, it is essential to have good communications across the above three departments - implying that an integrated structure or 'multidisciplinary project team' approach is a desirable factor for success.

For companies that do not possess these resources, or cannot harness them together as easily, it is more likely that an external specialist provider would be the best starting point.

Data linking can be a long and tortuous road and it is unwise to start off without a detailed route plan, together with a realistic assessment of the potential pitfalls and how these will be overcome. For example, an issue frequently encountered is whether the company holds sufficiently discriminatory information on all of its customers to be able to model the research results. It is better to address this problem at the outset and consider how it can be realistically solved, rather than hit it threequarters of the way through the project. The specialist provider should construct such a plan and risk assessment at the outset of the project.

\section{Conclusions}

Although they are both methods of collecting information, market research and customer research surveys differ from one another in several fundamental ways that have implications for merging the responses with customer data. It is essential that the potential user understands these differences in order to design the appropriate pathway of data collection and analysis to achieve their business objectives.

Failure to understand these issues may lead to research that gathers dust on the shelf because it cannot be applied to the customer base.

\footnotetext{
References

1. Webber, R. and Sleight, P. (1999) 'Fusion of market research and database marketing', Interactive Marketing, Vol. 1, No. 1.

2. Baker, K., Harris, P. and O'Brien, J. (1989) 'Data fusion: an appraisal and experimental evaluation', Journal of Market Research Society, Vol. 31, No. 2.

3. Market Research Society (1997) The MRS Code of Conduct.

4. Market Research Society (1996) Guidelines for Handling Databases

5. Webber and Sleight, ref 1 above.

6. Leventhal, B. (1997) 'An approach to fusing market research with database marketing,' Journal of Market Research Society, Vol. 39, No. 4.
} 